\title{
Constitution of the Alloys of Silver and Mercury.
}

THE physical characteristics of silver and mercury place formidable experimental difficulties in

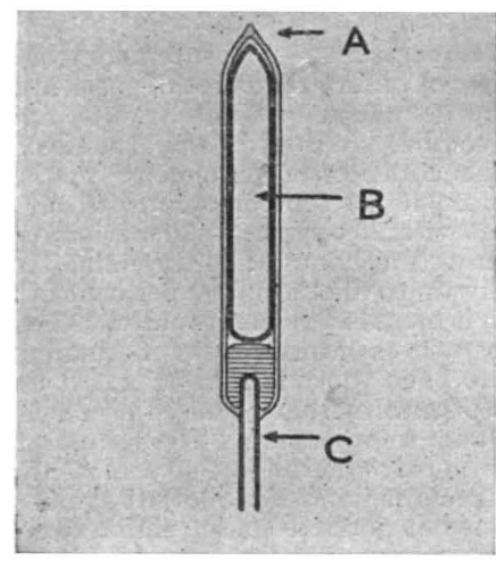

FIG. 1.

the way of any attempt to apply to this system of alloys the ordinary methods of physical metallurgy. At the melting point of silver the vapour pressure of mereury is about 250 atmospheres, and in overcoming the difficulties involved great credit is due to Dr. A. J. Murphy, who, in a paper read before the Institute of Metals on Sept. 15, has investigated this thermal equilibrium diagram.

In order to obtain the necessary heating and cooling curves, the metals, in a high state of purity, and, so far as the silver was concerned, in a very fine state of division, were placed in the fused silica vessel $A$ (Fig. 1), which at this stage was open. Into the tube $C$ the thermo-couple wires of chromel and alumel were introduced. It was not possible to seal off the tube $A$ at a distance less than $3 \mathrm{in}$. from the amalgam if undue heating were to be avoided, and to reduce the dead space that this entailed the closed silica tube $B$ was introduced. The outer silica tube was finally filled with hydrogen and sealed.

With most of the alloys it was necessary to apply a high pressure to the outer walls of $A$ to prevent explosion. For this purpose it was enclosed in a seamless steel bomb, fitted at both ends with massive caps which screwed down on to copperasbestos washers. The upper cap was provided with an inlet through which gas was passed at a pressure of 120 atmospheres. An internal electric furnace circuit was then closed and heating proceeded. No variation of the gas pressure was made during the observations owing to its liability to give rise to troublesome thermal effects.

The diagram deduced is shown in

No. 3243, VoL. 128]
Fig. 2. The a phase consists of a solid solution of the two metals. On heating to $276^{\circ} \mathrm{C}$., the $\beta$ phase dissociates into $\alpha$ and liquid, whilst the $\gamma$ phase similarly dissociates into $\beta$ and liquid at $127^{\circ} \mathrm{C}$. Although the exact nature of the $a$ and $\beta$ phases has not been determined, formulæ of the type $\mathrm{Ag}_{4} \mathrm{Hg}_{3}$ or $\mathrm{Ag}_{5} \mathrm{Hg}_{4}$ would satisfy the observations relating to the composition of the $\beta$ phase, and $\mathrm{Ag}_{3} \mathrm{Hg}_{4}$ or $\mathrm{Ag}_{4} \mathrm{Hg}_{6}$ for the $\gamma$ phase.

Although in general the vapour phase is neglected in dealing with most metallic systems, this can no longer be done in that under investigation without further consideration, since both the nature and the composition of the phases might be affected by the considerable pressure under which they were formed. It is of general interest, therefore, that the author shows that the actual phases present are independent of the pressure, and that, from an application of the Clapeyron equation, the temperatures at which transformations occur are not appreciably affected.

Figs. 1 and 2 are from Dr. Murphy's paper, by courtesy of the Institute of Metals.

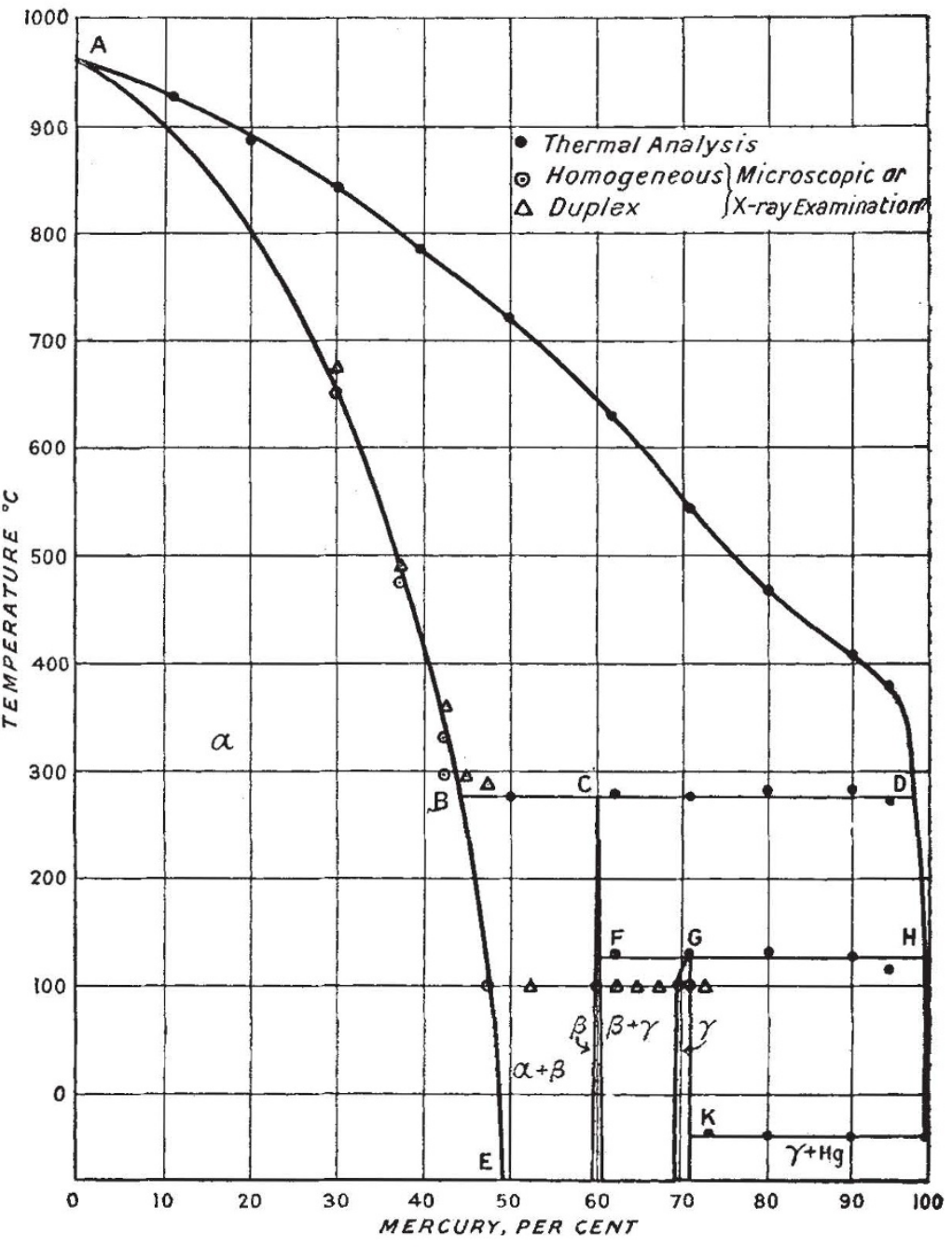

FrG. 2.-Equilibrium diagram of silver and mercury. 